\title{
Laser Additive Remanufacturing Parameters Optimization and Experimental Study of Heavy-Duty Sprocket
}

\section{Chenguang Guo}

Liaoning Technical University

Ning Lv

Liaoning Technical University

Haitao Yue ( $\sim$ htyue717@163.com )

Liaoning Technical University

Qiang Li

Liaoning Technical University

Jianzhuo Zhang

Liaoning Technical University

\section{Research Article}

Keywords: Laser additive remanufacturing, Heavy-duty sprocket, MOPSO algorithm, Parameters optimization

Posted Date: April 1st, 2021

DOI: https://doi.org/10.21203/rs.3.rs-371354/v1

License: (c) (i) This work is licensed under a Creative Commons Attribution 4.0 International License. Read Full License

Version of Record: A version of this preprint was published at The International Journal of Advanced Manufacturing Technology on October 18th, 2021. See the published version at https://doi.org/10.1007/s00170-021-08201-0. 


\title{
Laser Additive Remanufacturing Parameters Optimization and Experimental Study of Heavy-duty Sprocket
}

\author{
Chenguang Guo ${ }^{1,2}$, Ning Lv ${ }^{1}$, Haitao Yue ${ }^{1,2^{*}}$, Qiang Li ${ }^{1,2}$, Jianzhuo Zhang ${ }^{1,2}$ \\ (1. School of Mechanical Engineering, Liaoning Technical University, Fuxin, China; \\ 2. Liaoning Provincial Key Laboratory of Large-Scale Mining Equipment, Fuxin, China)
}

\begin{abstract}
Experimental research on laser additive remanufacturing technology of heavy-duty sprocket was carried out. The influences of laser power, scanning speed and powder feeding rate on cladding height, cladding area, melting area and dilution rate were compared and analyzed. The prediction models of the combination of process parameters with the geometric characteristics of cladding layer and dilution were established. A multi-objective process parameter optimization model with the maximum cladding height and cladding area maximum, the minimum melting area and dilution rate as objective functions was established, and the model was optimized and solved based on MOPSO algorithm. The laser additive remanufacturing repairing experiment of damaged sprocket was carried out by using the optimal parameters combination, and the microstructure and mechanical properties of the repaired region were analyzed. The results show that the scanning speed and powder feeding rate are the main factors influencing the geometric characteristics and dilution of the cladding area, and the models have good prediction accuracy. The optimal process parameters $(1150 \mathrm{~W}, 950 \mathrm{~mm} / \mathrm{min}, 3.8 \mathrm{rad} / \mathrm{min})$ obtained by MOPSO algorithm is adopted to repair the damaged sprocket. The repaired area without cracks and pores, the cladding layer shows good metallurgical bonding with the substrate and the microhardness is twice that of the substrate. The experimental results prove that the laser additive remanufacturing technology is feasible to repair the damaged heavy-duty sprocket and has a strong engineering application prospect.
\end{abstract}

Keywords: Laser additive remanufacturing; Heavy-duty sprocket; MOPSO algorithm; Parameters optimization

\section{Introduction}

Heavy-load sprocket is a significant component of power transmission for fully mechanized mining equipment. In the process of coal mining and transportation, the working conditions are harsh. The sprocket bears not only static load but also pulsating and impact load. The longtime engagement between the sprocket tooth and the chain causes severe wear of the tooth nest, the power transfer efficiency of fully mechanized mining equipment decreases, and the dynamic reliability and service life of the whole machine are significantly reduced. The research on remanufacturing and repairing technology of damaged sprocket has become the focus of manufacturing and operation maintenance service enterprises of fully mechanized mining equipment.

Many scholars have carried out a number of researches on remanufacturing and repair technology, such as brushing electroplating [1], arc welding [2], thermal spraying [3], hardfacing [4], plasma spraying [5], etc. However, these methods have many weaknesses that are not conducive to the quality control of mechanical parts repair, such as large heat-affected zone, uneven thermal stress distribution, poor precision, and the internal crack defects of the repair layer cannot be effectively regulated.

Laser additive remanufacturing technology, as an emerging repair technology, has the characteristics of low dilution rate, less porosity and crack defects, dense structure, rapid solidification, more cleanness, and a good combination of cladding layer and substrate [6-8]. Due to the above significant advantages, laser additive remanufacturing technology has been applied in such important fields as single crystal turbine blades [9], continuous caster lateral rolls [10], hydraulic piston rods [11], railway rails [12], and has achieved remarkable economic benefits. At present, many published works have reported on the research results of laser additive remanufacturing technology. For instance, Song [13] et al. used stainless steel powder as cladding material and adopted laser additive technology to

Corresponding author: Haitao Yue

E-mail: htyue717@163.com

Telephone: +8618841813958

Fax numbers: +864185110071 
process V-grooves on medium carbon steel substrates. They concluded that the cladding layer had a good fusion bond with the substrate, and the tensile strength, impacting toughness, elongation and microhardness of the rebuilt regions have been greatly enhanced. Qi [14] et al. proposed a geometry-based adaptive toolpath laser deposition method for the repair of blisk airfoils. The results show that the repair blisk blades have no obvious defects and have good dimensional accuracy. Rottwinkel [9] et al. investigated the crack repair of single crystal turbine blades using laser cladding technology. It could be shown successfully that inductive preheating leads to a crack-free clad, and laser cladding technology can be an efficient method to repair single crystal turbine blades. Ray [10] et al. utilized laser cladding technology to enhance the service life of caster lateral rolls, which significantly improved the wear resistance and corrosion resistance of the side roller. J. Tuominen [11] et al. prepared a laser cladding repair layer on a worn hydraulic piston rod to improve the surface hardness, wear resistance, corrosion resistance and fatigue strength of the piston rod. Robles [12] et al. put forward a set of laser additive repair technologies, including thermal analysis, heat treatment, numerical simulation and performance testing, which can increase the rail tracks service life up to $1400 \%$ when compared to those of initial state. Xu [15], Penaranda [16] and Stefan [17] et al. successfully applied laser additive remanufacturing technology to the repair process of the blade tip and achieved good repair results. Liu [18] et al. determined the optimal process parameters of sprocket repair according to the low dilution rate. The processing experiment found that the size error of the repaired sprocket is small, the microhardness of the cladding layer is high, and the cladding layer forms metallurgical bonding with the substrate.

In summary, laser additive remanufacturing technology has been proven to be an effective way to achieve successful repairing of mechanical parts [18]. In this paper, the experimental research on laser additive remanufacturing of heavy-load sprocket used in mining was carried out. The effects of process parameters such as laser power $P$, scanning speed $V$ and powder feeding rate $F$ on the geometric characteristics of single clad tracks, such as cladding high $H_{C}$, cladding zone area $A_{C}$, fusion zone area $A_{m i x}$ and dilution ratio $D$ are analyzed in detail. The prediction models between process parameters and geometric characteristics (i.e. $\left.H_{C}, A_{C}, A_{m i x}, D\right)$ of single clad tracks were established as a combined parameter $\left(y=k\left(P^{\alpha} V^{\beta} F^{\lambda}\right)+b\right)$ respectively. A multi-objective process parameter optimization model for laser additive remanufacturing was constructed with the objective function of maximum cladding high $H_{C}$, the maximum cladding zone area $A_{C}$, the minimum fusion zone area $A_{m i x}$ and the minimum dilution ratio $D$. The validation experiment of the laser additive remanufacturing of double-row heavy-load sprocket was carried out, and the microstructure and mechanical properties of the repaired sprocket tooth nest were evaluated.

\section{Experimental materials and method}

\subsection{Materials and equipment}

The substrate plate is AISI 4340 with the structure dimensions of $40 \mathrm{~mm} \times 30 \mathrm{~mm} \times 20 \mathrm{~mm}$. Before performing the experiment, substrate plate must first be polished and wiped with alcohol and acetone to remove surface rust, grease and other stains. A Fe-Cr based alloy material was adopted as the laser cladding powder in which particle size is 30 200 $\mu \mathrm{m}$. The morphology, particle size and composition of the powder material is respectively shown in Fig. 1 and Table 1. In order to prevent moisture from affecting powder liquidity, $4 \mathrm{~h}$ insulation drying at $80^{\circ} \mathrm{C}$ of the powder should be taken before the cladding process.

The experimental research of laser additive remanufacturing of heavy-load sprocket was carried out on a four-axis linkage numerical control platform. The workbench can realize 3-axis (X, Y, Z) movement, and the sprocket was clamped on the turntable to achieve rotational motion. A $3000 \mathrm{~W}$ fiber-coupled diode laser with a continuous wavelength of 900 1080nm was utilized. IWS-COAX8 coaxial powder feeding nozzle and PF2/2 powder feeder were used for coaxial powder feeding, and the powder carrier and protective high purity argon was adopted to isolate oxidation.

After disposing accomplished all the cladding processing experiments, specimens were subjected to cutting, grinding, polishing, corrosion $\left(\mathrm{C}_{2} \mathrm{H}_{5} \mathrm{OH}: \mathrm{HNO}_{3}=24: 1\right.$, vol. \%), cleaning and drying to prepare as analytical samples. The geometric characteristics of each cladding track cross-section were measured using the optical digital microscope (VHX-5000). The cross-section microstructure of cladding layer was observed by metallographic microscope (ZEISS 
Axio Scope A1), and the Vickers hardness of specimens was measured by microhardness tester (Akashi MVK-H11).

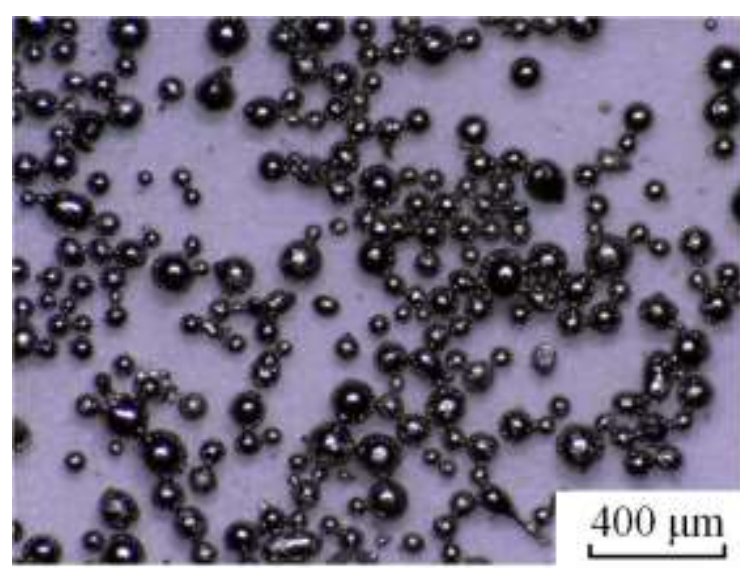

(a) Morphology of powder

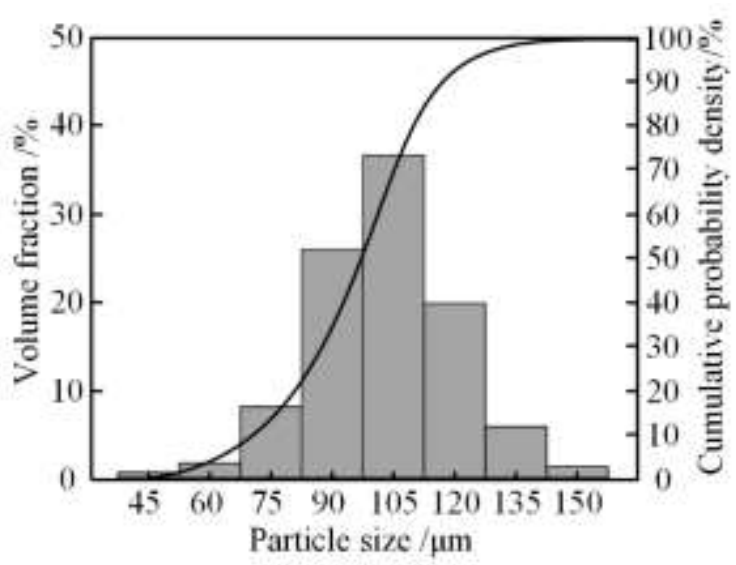

(b) Particle size

Figure1 The morphology and particle size of cladding powder material

Table 1 Composition of AISI 4340 and FeCr alloy powder

\begin{tabular}{ccc}
\hline Element & AISI 4340 & FeCr alloy powder \\
\hline $\mathrm{Gr}$ & 1.5 & 16.79 \\
$\mathrm{Si}$ & $0.25-0.30$ & 4.0 \\
$\mathrm{~B}$ & - & 3.5 \\
$\mathrm{Cu}$ & - & 3.0 \\
$\mathrm{Mo}$ & 0.2 & 3.0 \\
$\mathrm{Ni}$ & 1.55 & 2.14 \\
$\mathrm{C}$ & 0.34 & 0.23 \\
$\mathrm{P}$ & - & 0.007 \\
$\mathrm{~S}$ & - & 0.005 \\
$\mathrm{Mn}$ & 0.5 & - \\
$\mathrm{Fe}$ & $\mathrm{Bal}$. & Bal. \\
\hline
\end{tabular}

\subsection{Experimental method}

As shown in Fig. 2, the geometric characteristics of single cladding layer usually include cladding high $\left(H_{C}\right)$, cladding width $\left(W_{C}\right)$, cladding zone area $\left(A_{C}\right)$, fusion zone area $\left(A_{m i x}\right)$, cladding depth $\left(H_{m i x}\right)$ and heat-affected zone (HAZ). Dilution ratio refers to the degree of material composition changes in the fusion zone caused by the heat fusion of the substrate material during the laser cladding process. Dilution ratio is a significant index to measure the quality state of laser cladding. The calculation method of dilution ratio in this paper is shown in Eq. (1) $[19,20]$.

$$
D=\frac{A_{\text {mix }}}{A_{\text {mix }}+A_{C}} \times 100 \%
$$

The geometry is greatly affected by the process parameters [21]. According to the kinds of literature [22, 23, 24], laser power $(P)$, scanning speed $(V)$, and powder feeding rate $(F)$ is the most important factor affecting the geometric characteristics of the cladding layer. The detailed orthogonal experimental schemes are listed in table 2 . The geometry parameters, namely cladding high $\left(H_{C}\right)$, cladding area $\left(A_{C}\right)$, fusion zone area $\left(A_{m i x}\right)$ and dilution ratio $(D)$ of cladding cross-section were chosen as evaluation indexes of geometric characteristics of the cladding layer. Table 3 lists the measurement results of the evaluation indexes of the geometric characteristics of the clad tracks under various process parameters. 
Table 2 Factors and levels of process parameters

\begin{tabular}{cccccc}
\hline Factor & Process parameters & Level 1 & Level 2 & Level 3 & Level 4 \\
\hline A & Laser power $P / \mathrm{W}$ & 1100 & 1200 & 1300 & 1400 \\
B & Scanning speed $\mathrm{V} / \mathrm{mm} \cdot \mathrm{min}^{-1}$ & 700 & 800 & 900 & 1000 \\
C & Powder feeding rate $F / \mathrm{rad} \cdot \mathrm{min}^{-1}$ & 2.9 & 3.2 & 3.5 & 3.8 \\
\hline
\end{tabular}

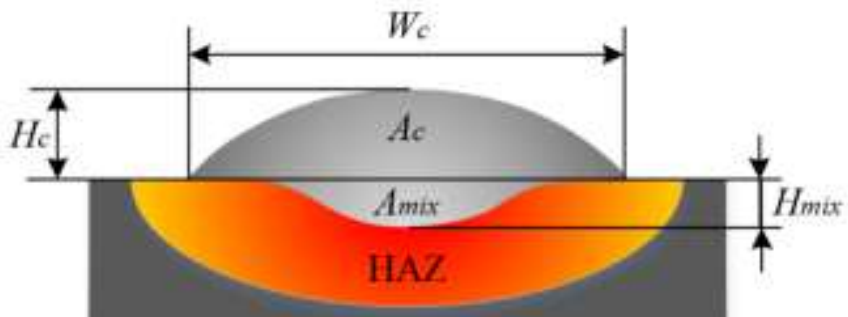

Substrate

Figure 2 Schematic of single cladding track cross-section

Table 3 Orthogonal experimental schemes and results of single cladding track

\begin{tabular}{cccccccc}
\hline No. & $\begin{array}{c}\text { Laser } \\
\text { power } \\
P / \mathrm{W}\end{array}$ & $\begin{array}{c}\text { Scanning } \\
\text { speed } \\
V / \mathrm{mm} \bullet \mathrm{min}^{-1}\end{array}$ & $\begin{array}{c}\text { Powder } \\
\text { feeding rate } \\
F / \text { rad } \bullet \mathrm{min}^{-1}\end{array}$ & $\begin{array}{c}\text { Cladding } \\
\text { height } \\
H_{C} / \mathrm{mm}\end{array}$ & $\begin{array}{c}\text { Cladding } \\
\text { zone area } \\
A_{C} / \mathrm{mm}^{2}\end{array}$ & $\begin{array}{c}\text { Fusion zone } \\
\text { area } \\
A_{\text {mix }} / \mathrm{mm}^{2}\end{array}$ & $\begin{array}{c}\text { Dilution } \\
\text { ratio } \\
D / \%\end{array}$ \\
\hline 1 & 1100 & 700 & 2.9 & 0.401 & 0.751 & 0.094 & 11.12 \\
2 & 1100 & 800 & 3.2 & 0.370 & 0.740 & 0.089 & 10.74 \\
3 & 1100 & 900 & 3.5 & 0.364 & 0.726 & 0.079 & 9.81 \\
4 & 1100 & 1000 & 3.8 & 0.357 & 0.733 & 0.068 & 8.49 \\
5 & 1200 & 700 & 3.2 & 0.435 & 0.850 & 0.102 & 10.71 \\
6 & 1200 & 800 & 2.9 & 0.353 & 0.726 & 0.092 & 11.25 \\
7 & 1200 & 900 & 3.8 & 0.422 & 0.878 & 0.083 & 8.63 \\
8 & 1200 & 1000 & 3.5 & 0.334 & 0.689 & 0.073 & 9.58 \\
9 & 1300 & 700 & 3.5 & 0.456 & 0.960 & 0.116 & 10.78 \\
10 & 1300 & 800 & 3.8 & 0.461 & 0.966 & 0.097 & 9.13 \\
11 & 1300 & 900 & 2.9 & 0.336 & 0.697 & 0.086 & 10.98 \\
12 & 1300 & 1000 & 3.2 & 0.323 & 0.641 & 0.074 & 10.35 \\
13 & 1400 & 700 & 3.8 & 0.489 & 1.079 & 0.114 & 9.56 \\
14 & 1400 & 800 & 3.5 & 0.383 & 0.813 & 0.098 & 10.78 \\
15 & 1400 & 900 & 3.2 & 0.360 & 0.741 & 0.091 & 10.94 \\
16 & 1400 & 1000 & 2.9 & 0.294 & 0.511 & 0.062 & 10.82 \\
\hline
\end{tabular}

\section{Results and discussion}

\subsection{Analysis of experimental results}

Fig. 3 shows the influence trend of numerous factors and levels on cladding geometry, involve of cladding high $\left(H_{C}\right)$, cladding zone area $\left(A_{C}\right)$, fusion zone area $\left(A_{m i x}\right)$ and dilution ratio $(D)$. The cladding high $\left(H_{C}\right)$ presents a trend of first increasing and then decreasing with the increase of laser power $P$, which can principally be ascribed to the rise in laser irradiation energy absorbed by the molten pool with the addition of laser power, the amount of fusional powder in the molten pool increases, and the cladding high presents a trend of gradually increasing. However, when the laser power exceeds the threshold value, the powder is prone to gasification or even the formation of plasma. The liquid metal in the molten pool fluctuates violently and extends to both sides, resulting in a downward trend of the cladding high. There is 
a strong linear relationship exhibit between scanning speed $(V)$ and cladding high $\left(H_{C}\right)$, which is also reflected in the relationship between powder feeding rate $(F)$ and cladding high $\left(H_{C}\right)$. With the increase of scanning speed $(V)$ or the decrease of powder feeding rate $(F)$, the laser irradiation energy and powder quantity involved in the reaction decrease, and the cladding high decreases significantly.

As the laser power $(P)$ increases, the cladding zone area $\left(A_{C}\right)$ also appears to increase first and then decrease (as shown in Fig. 3b) with the same trend as that of cladding high $\left(H_{C}\right)$ in Fig. 3(a). There is a negative correlation between scanning speed $(V)$ and cladding zone area $\left(A_{C}\right)$, and the powder feeding rate $(F)$ has a positive influence on cladding zone area $\left(A_{C}\right)$, which is due to the reduction of the powder feeding rate per unit time with the increase of the scanning speed or the decrease of the powder feeding rate.

From Fig. 3(c), the fusion zone area $\left(A_{m i x}\right)$ shows a downward trend after initially rise with the increase of powder feeding rate $(F)$. This is since with the increase in the amount of powder entering the laser irradiation zone, the powder absorbs more laser irradiation energy and the substrate material gets insufficient melting, resulting in a declining trend of the cladding fusion zone area after reaching the critical state.

As shown in Fig. 3 (d), the dilution ratio $(D)$ gradually increases with the rise of laser power $(P)$ but decreases with the increase of the scanning speed $(V)$ and the powder feeding rate $(F)$. In the case where the laser power and the scanning speed are constant, the powder feeding rate determines the ratio of the energy absorbed by the powder and the substrate. With the increase of powder feeding rate, the cladding zone area increases, the absorption energy of the substrate decreases, and the fusion zone area is reduced. Cladding zone area and fusion zone area change oppositely, resulting in an obvious phenomenon that the dilution ratio changes with the powder feeding rate.

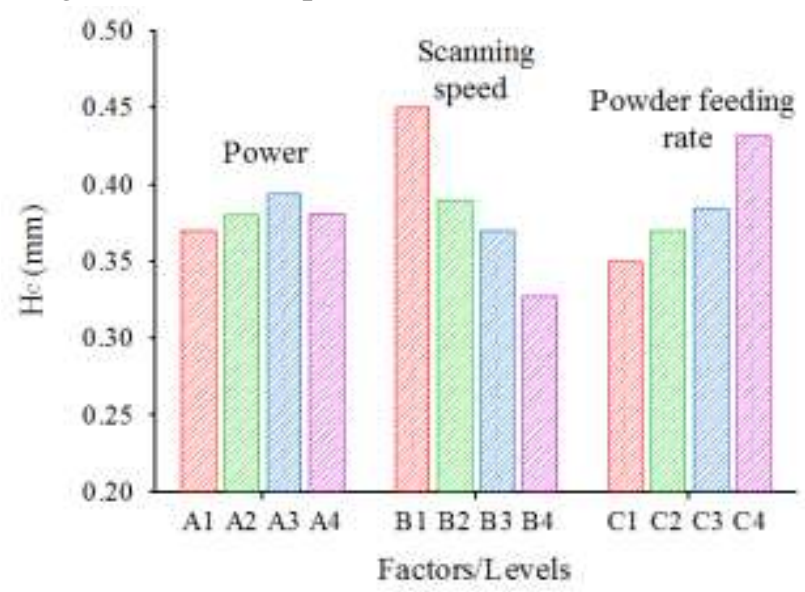

(a)

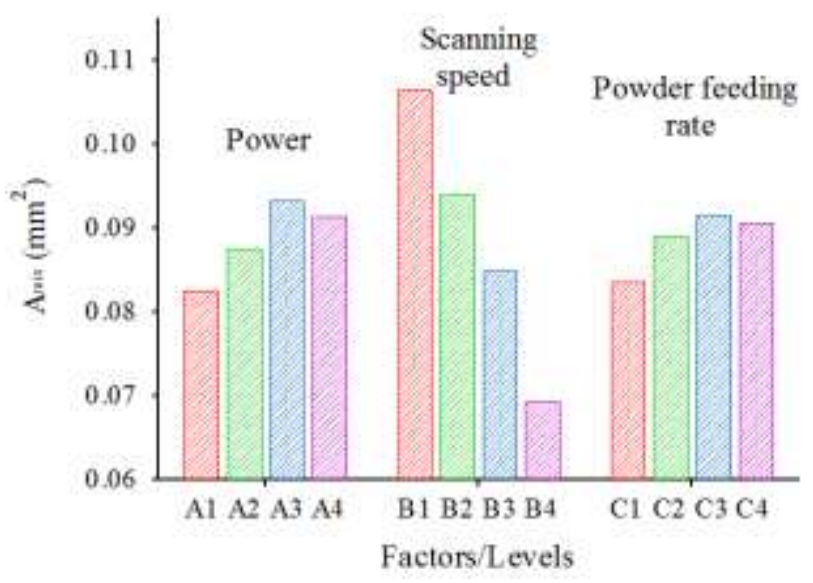

(c)

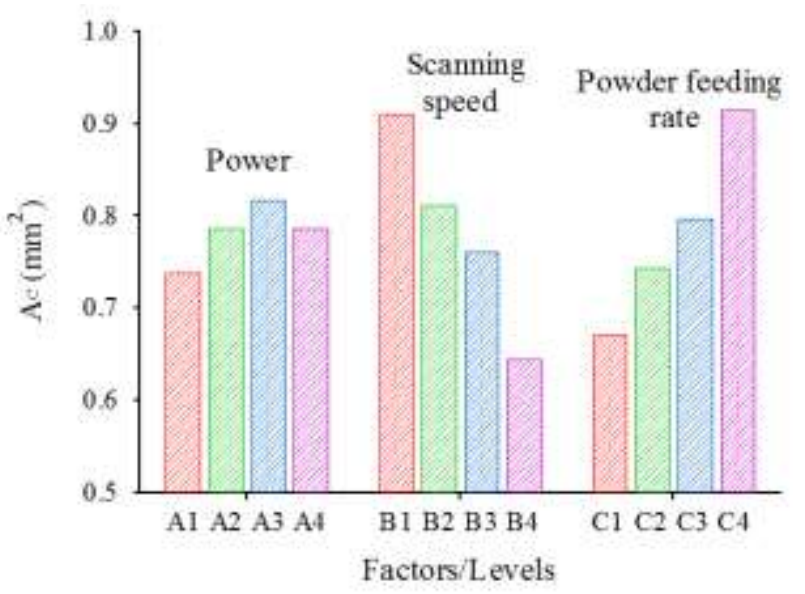

(b)

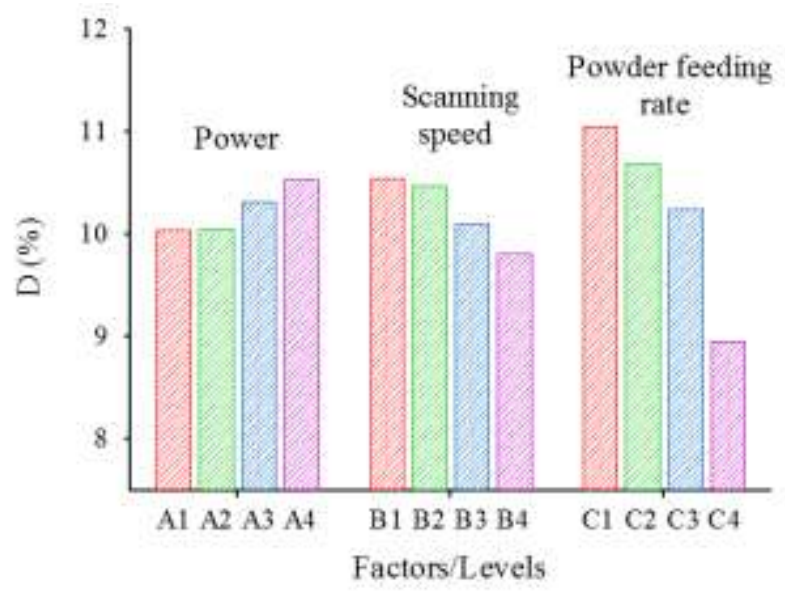

(d)

Figure 3 The trend chart of geometric characteristics and dilution rate

\subsection{Prediction model}

It is meaningful to set up a prediction model between process parameters and geometric characteristics of cladding 
layer [7]. As shown in Eq. (2), Cheikh [25] established a prediction model, which can forecast the geometric characteristics of the laser cladding layer through processing parameters.

$$
y=k\left(P^{\alpha} V^{\beta} F^{\lambda}\right)+b
$$

Where $y$ is one of the geometry parameters of the cross-section while $k$ and $b$ are constants. $\alpha, \beta$ and $\lambda$ are the index of process parameter laser power $(P)$, scanning speed $(V)$ and powder feed rate $(F)$ respectively. The same formula was utilized to predict the interrelation between the process parameters (laser power $(P)$, scanning speed $(V)$, and powder feeding rate $(F))$ of laser cladding and the geometric parameters [26] of a single laser tracks (cladding high $\left(H_{C}\right)$, cladding zone area $\left(A_{C}\right)$, fusion zone area $\left(A_{m i x}\right)$ and dilution ratio $\left.(D)\right)$.

By calculating the predicted model of cladding high $\left(H_{C}\right)$ can be calculated by formula $H_{C}=21.77 P^{-0.0330} V^{-0.6614} F^{0.6911}$ -0.0784 with a correlation coefficient $R^{2}=0.9365$ (as shown in Fig. 4a), and the measured value of the cladding high has a strong correlation with the predicted value. The index of laser power $(P)$ approaches to 0 , which indicates that the coefficient of laser power has little effect on the cladding high. The index of the scanning speed $(V)$ is -0.6614 , indicating that the scanning speed has a negative influence on the cladding high. The index 0.6911 of powder feeding rate $(F)$ indicates that powder feeding has a positive effect on cladding high. The prediction model calculation results are consistent with the experimental analysis results, and Fig. 4(b) demonstrates the residuals of the prediction model of cladding high.

The predicted model of cladding zone area $\left(A_{C}\right)$ can be calculated by formula $A_{C}=33.34 P^{0.1519} V^{-0.9189} F^{1.1024}+0.0101$ with a correlation coefficient $R^{2}=0.9334$ (as shown in Fig. 4c) which indicates that the predicted model results have a good correlation with the experimental results. Similar to the prediction model of cladding high $\left(H_{C}\right)$, the index 0.1519 of laser power $(P)$ indicates that laser power has a weak effect on cladding zone area. The index of scanning speed $(V)$ and powder feeding rate $(F)$ are -0.9189 and 1.1024 respectively, which indicates they both have a vital effect on cladding zone area. However, the index of scanning speed is a negative number, which means it has a substantial negative impact on cladding zone area. The residual diagram in Fig. 4(d) verifies the accuracy of the predicted model.

Meanwhile, the fusion zone area $\left(A_{m i x}\right)$ also can be calculated by formula $A_{m i x}=9.25 P^{0.3919} V^{-1.1607} F^{0.2794}+0.0025$ with a correlation coefficient $R^{2}=0.8663$ (as shown in Fig. 4e). The index of scanning speed $(V)$, laser power $(P)$ and powder feeding rate $(F)$ are $-1.1607,0.3919$ and 0.2794 respectively. The index which is more than -1 shows that scanning speed $(V)$ has the most negative effect on the area of fusion zone area. These predictions are also consistent with the analysis in Section 2.1. Fig. 4(f) indicates the residuals of the prediction model of fusion zone area.

The predicted model of dilution ratio $(D)$ can be calculated by formula $D=21.16 P^{0.2214} V^{-0.2418} F^{-0.7382}+0.2758$ with a correlation coefficient $R^{2}=0.8663$ (as shown in Fig. 4g) and superior residuals (as shown in Fig. 4h). The index of laser power $(P)$ and scanning speed $(V)$ are 0.2214 and -0.2418 respectively, which indicates they both have a slight effect on dilution ratio. The powder feeding rate index reached 0.7382 , indicating that the dilution ratio varies obviously with the increase of powder feeding rate, which is consistent with the prediction model fitting results.

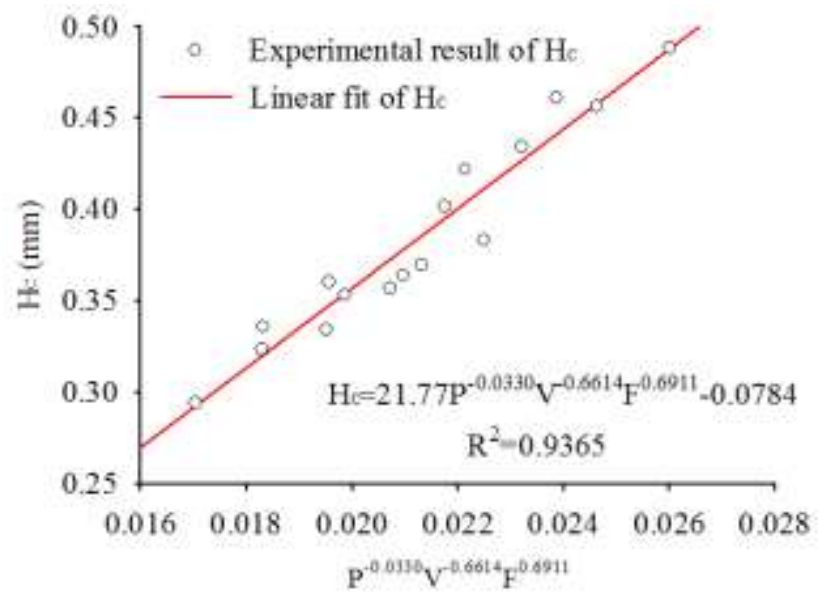

(a)

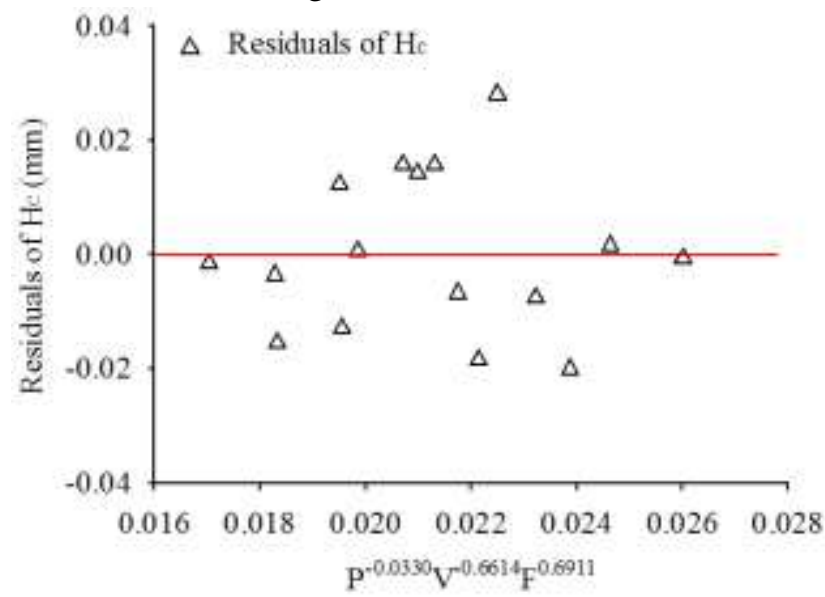

(b) 


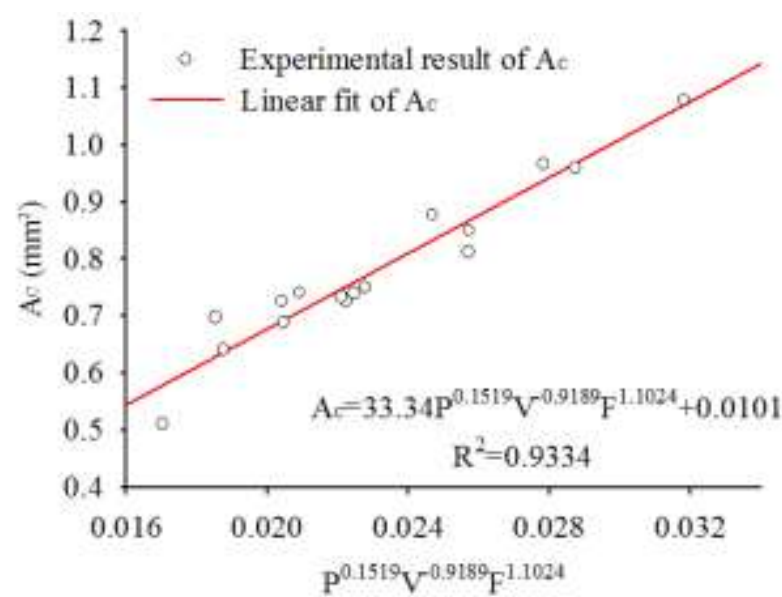

(c)

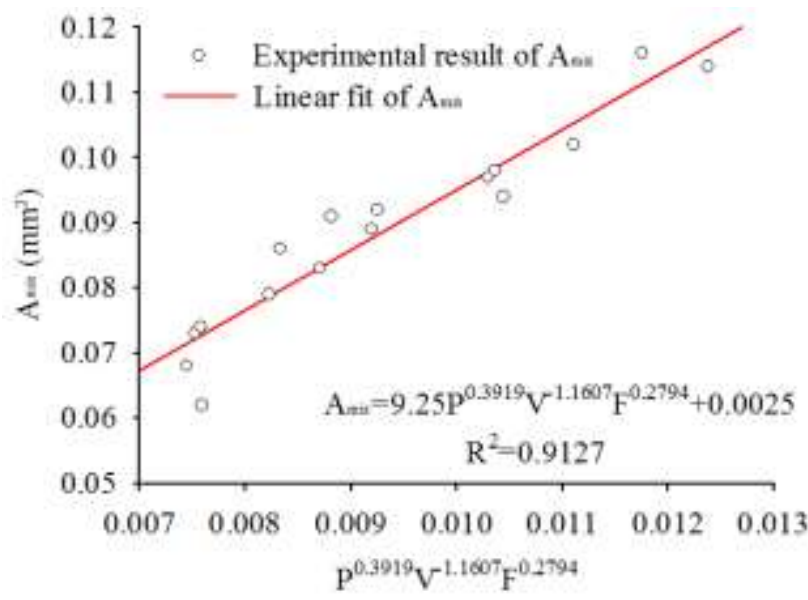

(e)

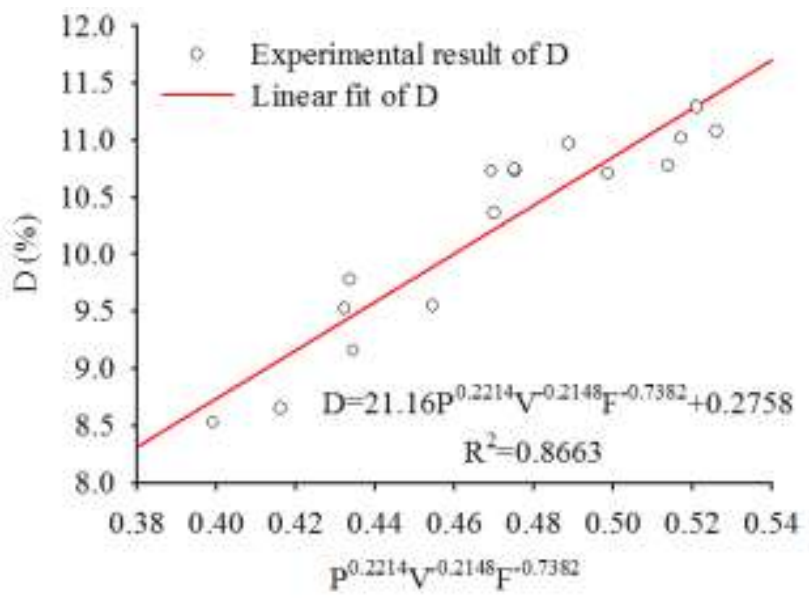

(g)

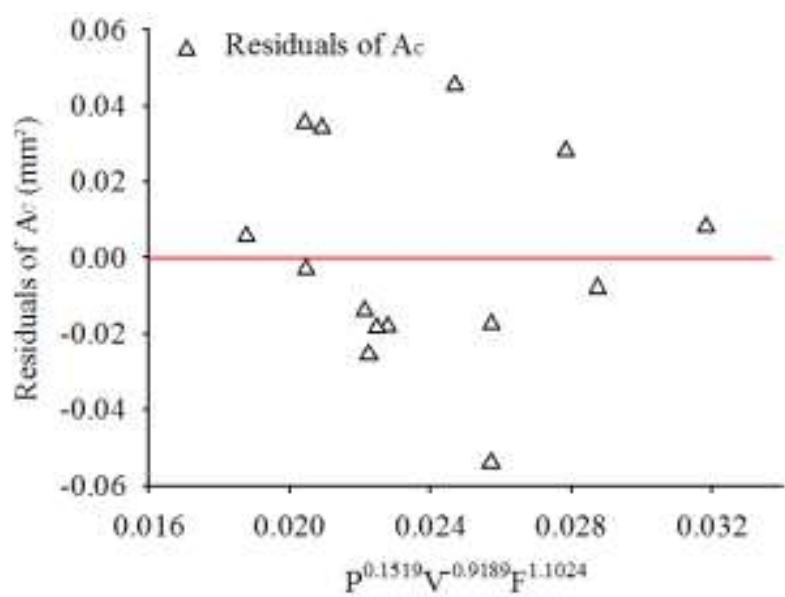

(d)

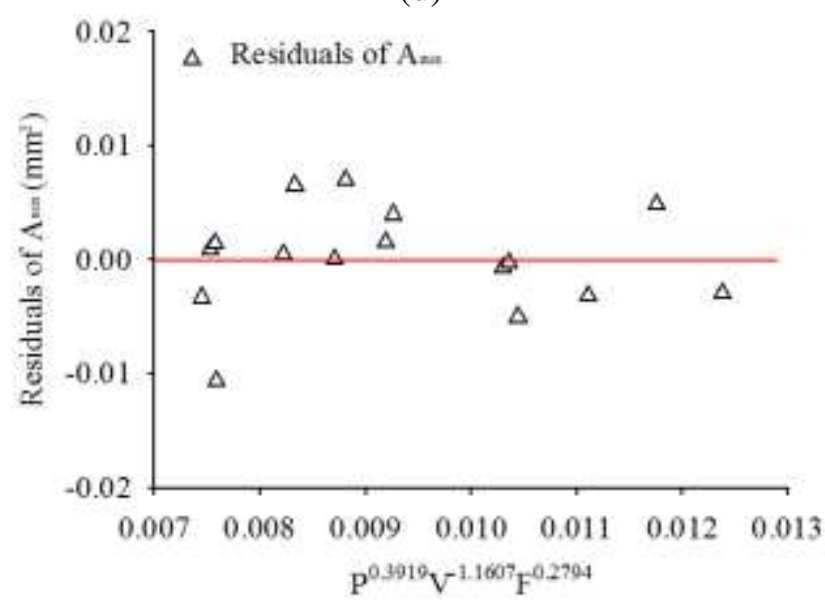

(f)

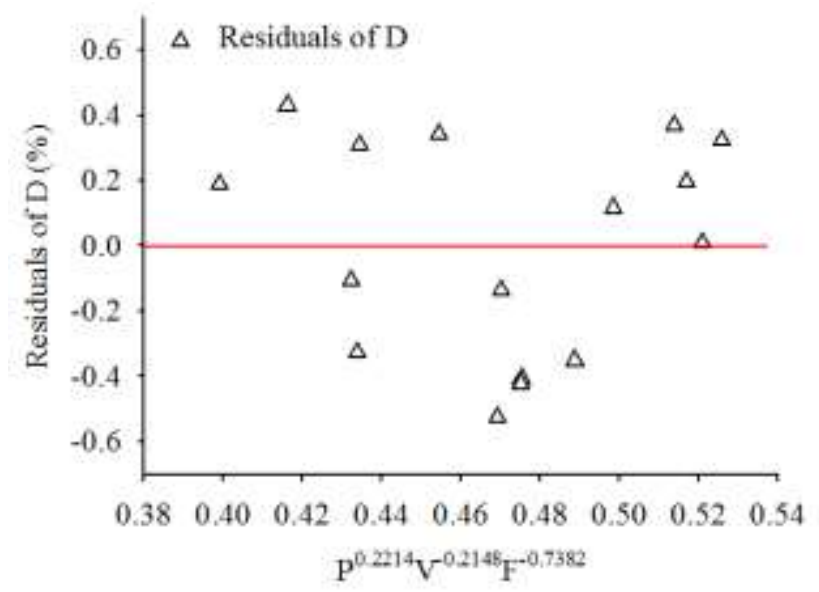

(h)

Figure 4 Prediction model between $H_{C}, A_{C}, A_{m i x}, D$ with process parameters and residuals

\section{Laser additive remanufacturing of the sprocket}

\subsection{Processing parameters}

There is much sense that a strong intermixture and metallurgical bond with minimum dilution can be provided by laser cladding [21]. Many studies have indicated that the cladding layer of low dilution rate has well microstructure and mechanical properties [21,27]. As shown in Eq. (3), in order to reduce the energy consumption of the processing process and improve the metallurgical bonding between the substrate and the cladding layer, a multi-objective optimization problem was constructed with maximizing cladding high $\left(H_{C}\right)$, maximizing cladding zone area $\left(A_{C}\right)$, minimizing fusion zone area $\left(A_{m i x}\right)$ and minimizing dilution ratio $(D)$. 


$$
\left\{\begin{array}{l}
\max \left\{H_{C}(P, V, F), A_{C}(P, V, F)\right\} \\
\min \left\{A_{\text {mix }}(P, V, F), D(P, V, F)\right\} \\
1100 \leq P \leq 1400 \\
700 \leq V \leq 1000 \\
2.9 \leq F \leq 3.8
\end{array}\right.
$$

MOPSO algorithm is extensively utilized in multi-objective optimization of manufacturing process [28]. In this paper, the MOPSO algorithm was applied to complete the optimization solution of the multi-objective optimization model. In the solving process of MOPSO, the population size was $N=100$, the number of iterations was $I=2000$, the maximum inertia weight was $\omega_{\max }=0.9$, the minimum inertia weight was $\omega_{\min }=0.9$, the learning factor $c_{1}=c_{2}=2$. The multi-objective model optimization results are shown in Fig. 5 where each point represents an optimal solution in the Pareto frontier solution set.

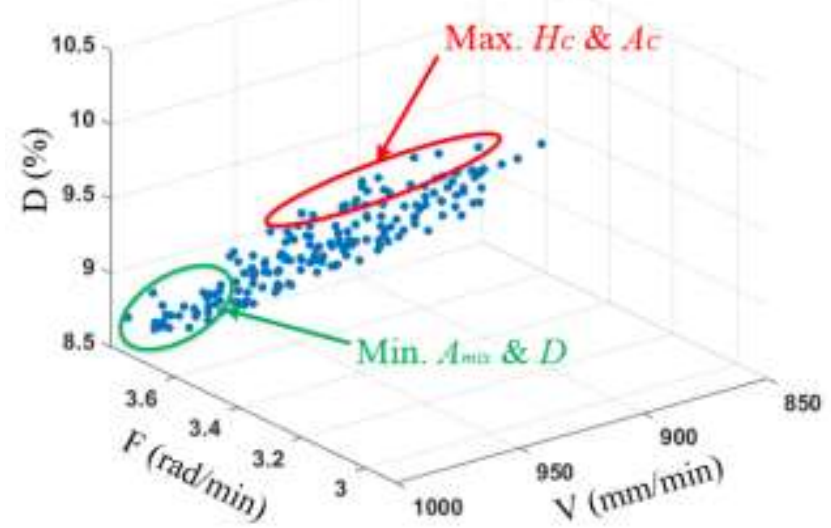

(a) Dilution ratio

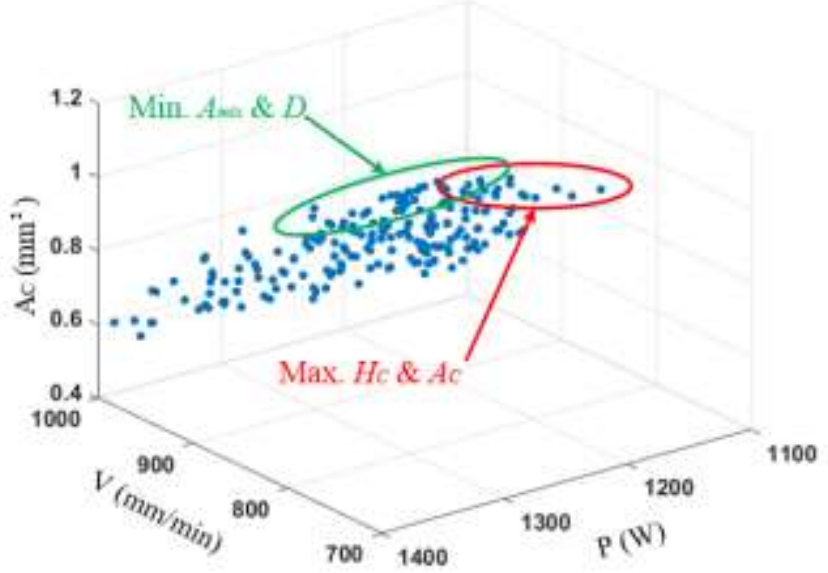

(b) Cladding zone area

Figure 5 Multi-objective model optimization results

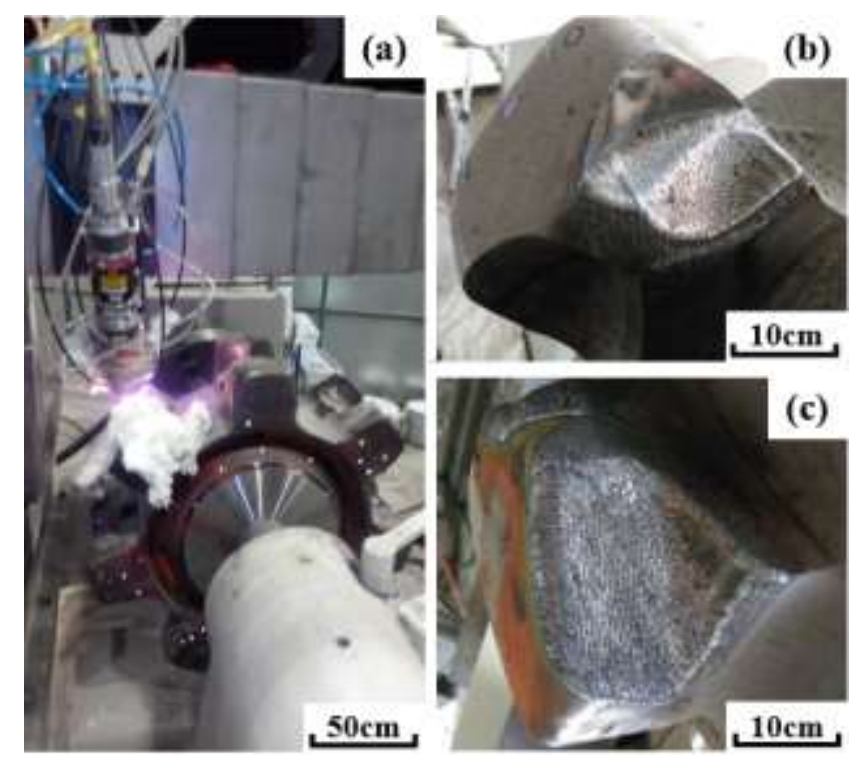

Figure 6 Sprocket remanufacturing process and its repair state

According to the analysis in Sections 2.1 and 2.2, the powder feeding rate $(F)$ is the most important factor affecting the dilution ratio $(D)$. As shown in Fig. 5(a), when the powder feeding rate $F=3.8 \mathrm{rad} / \mathrm{min}$ and the scanning speed $V=900 \sim 950 \mathrm{~mm} / \mathrm{min}$, the dilution ratio and the fusion zone area are minimized, while the cladding high and the cladding zone area reach the maximum. Fig. 5 (b) shows that when the laser power $P=1150 \mathrm{~W}$ and the scanning speed $V=950$ $\mathrm{mm} / \mathrm{min}$, the multi-objective optimization model can obtain the maximum cladding high and cladding zone area, as well as the minimum fusion zone area and dilution ratio. Then the optimal process parameters of sprocket remanufacturing are as follows: laser power $P=1150 \mathrm{~W}$, scanning speed $V=950 \mathrm{~mm} / \mathrm{min}$, powder feeding rate $F=3.8 \mathrm{rad} / \mathrm{min}$. The process 
of sprocket remanufacturing using the optimal process parameters determined in this study is shown in Fig. 6. A zigzag laser cladding tool path was adopted in the process of sprocket remanufacturing. The overlap rate of the adjacent cladding tracks was $45 \%$ and the lifting amount of each cladding layer along the Z-axis was $0.4 \mathrm{~mm}$. Fig. 6(c) shows the final repair state of the sprocket tooth.

\subsection{Microstructure}

Characterized in Fig.7 is the microstructure from the cladding region of the partial repairing sprocket tooth. It is obvious that the microstructure of a cladding layer composes of heat-affected zone of the substrate, interfacial diffusion zone, and cladding zone. As seen in Fig. 7(a), the heat-affected zone and the interfacial diffusion zone have a layer of chilled zone structure, which is a luminous white area formed at the interface junction between the substrate and cladding layer, exhibiting a superb metallurgical bonding between the cladding zone and substrate. Columnar crystal and dendritic crystal along the heat transfer direction can be seen at the cladding zone, as shown in Fig. 7(b) and 7(c). Liu [29] believes that the change of grain morphology of metallographic structure is caused by the difference of ratio of temperature gradient to solidification rate (i.e., $\mathrm{G} / \mathrm{R}$ ) at different positions during solidification. In the process of laser cladding, the cladding layer dissipates main heat through the substrate, resulting in the maximum temperature gradient along with the perpendicular interface. $\mathrm{G} / \mathrm{R}$ at the interface between the substrate and the fusion zone is relatively high, so it is easy to form columnar dendrites. With the development of solidification process and the accumulation of heat, the temperature gradient decreases gradually, and the cladding region exhibits an increases tendency to dissipate heat to the outside. The cooling rate of the outer surface of the cladding region is accelerated to form dendritic crystals and tends to shift to smaller crystal structure. It can be seen from the metallographic structure of heat-affected zone materials in Fig. 7(d) that the non-layered structure composed of ferrite and cementite is the performance of austenitization of crystal structure in the heat-affected zone after laser irradiation, and the non-layered structure has a stable strength and toughness coordination. In general, the sprocket cladding area is uniform and dense, the fusion zone and the substrate are well metallurgically bonded, and there are no micro cracks and defects generated.

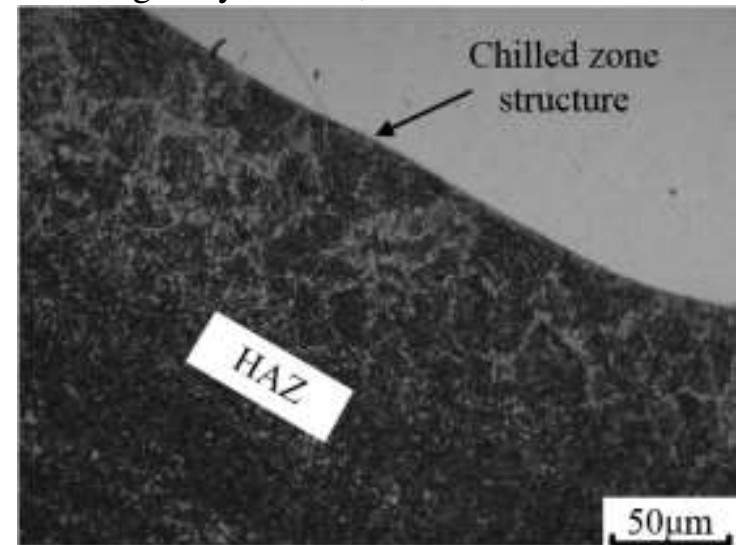

(a) Cladding zone and substrate

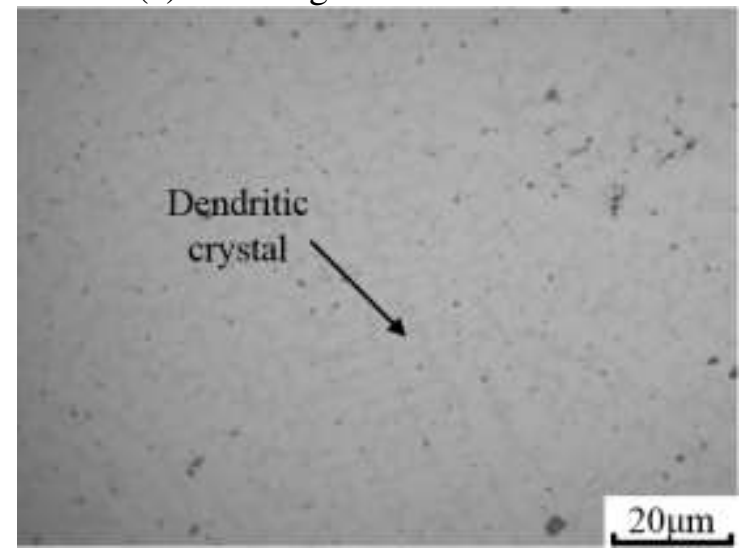

(c) Dendritic crystal

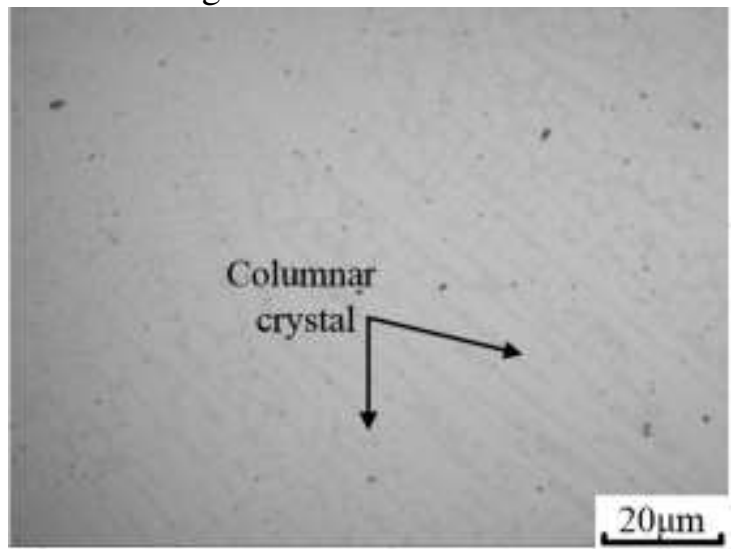

(b) Columnar crystal

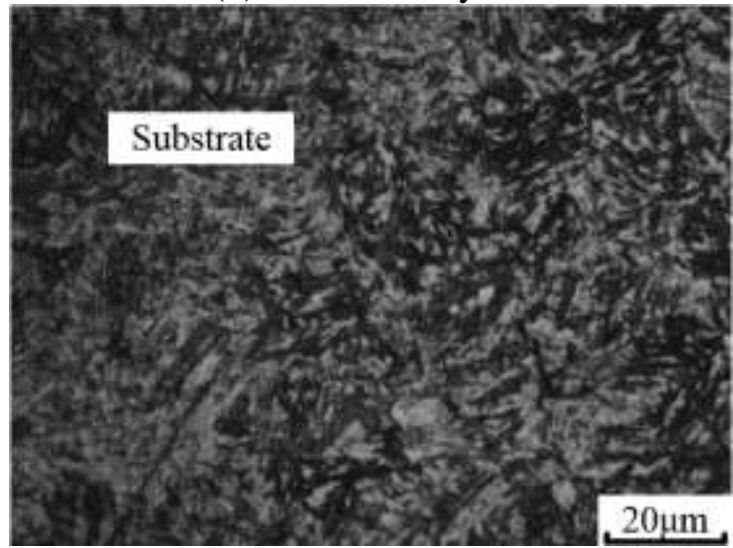

(d) Heat-affected zone

Figure 7 Metallographic morphology of the cladding area 


\subsection{Microhardness}

The microhardness of the specimen was measured by selecting 20 measuring points (Distance between each measuring point is $0.1 \mathrm{~mm}$, and there are 10 measuring points in the coating zone, which is $1 \mathrm{~mm}$ distance from the cladding area to the substrate) evenly along the direction of the cladding area to the cross section of the substrate. Fig. 8 shows the change curve of microhardness from the cladding area to the substrate. The microhardness decreases gradually from the cladding area to the heat-affected region and the substrate. It can be seen that the microhardness of the cladding area can reach $550 \mathrm{HV} \sim 650 \mathrm{HV}$, which is notably superior to the substrate $(350 \mathrm{HV})$. The reason for this trend is that there are a lot of alloying elements in the cladding powder, which leads to the enhancement of the solid solution strengthening between the elements inside the cladding layer, resulting in a higher hardness of the cladding layer than the hardness of the substrate. As the measuring point moves toward the fusion zone, the hardness gradually decreases but is higher than the hardness of the substrate. This is due to the dispersion phenomenon of eutectic compounds in the fusion zone, which plays the role of hardness strengthening. Meanwhile, the rapid solidification leads to uniform and dense metallographic structure, resulting in the phenomenon that the hardness of the fusion zone is higher than the base substrate but lower than that of the cladding layer. When the measuring point enters the heat-affected zone, the decreasing trend of hardness slows down. The main reason is that the heat-affected zone is quenched under the action of high temperature, and a small number of alloy elements in the fusion zone diffuse into the heat-affected zone so that the hardness of the heat-affected zone is lower than that of the fusion zone but slightly higher than that of the substrate. When the measuring point leaves the heat-affected zone and enters the substrate, the hardness changes tend to be stable. It demonstrates that the laser cladding technology can significantly improve the microhardness and wear resistance of sprocket tooth in the cladding area of the remanufactured sprocket.

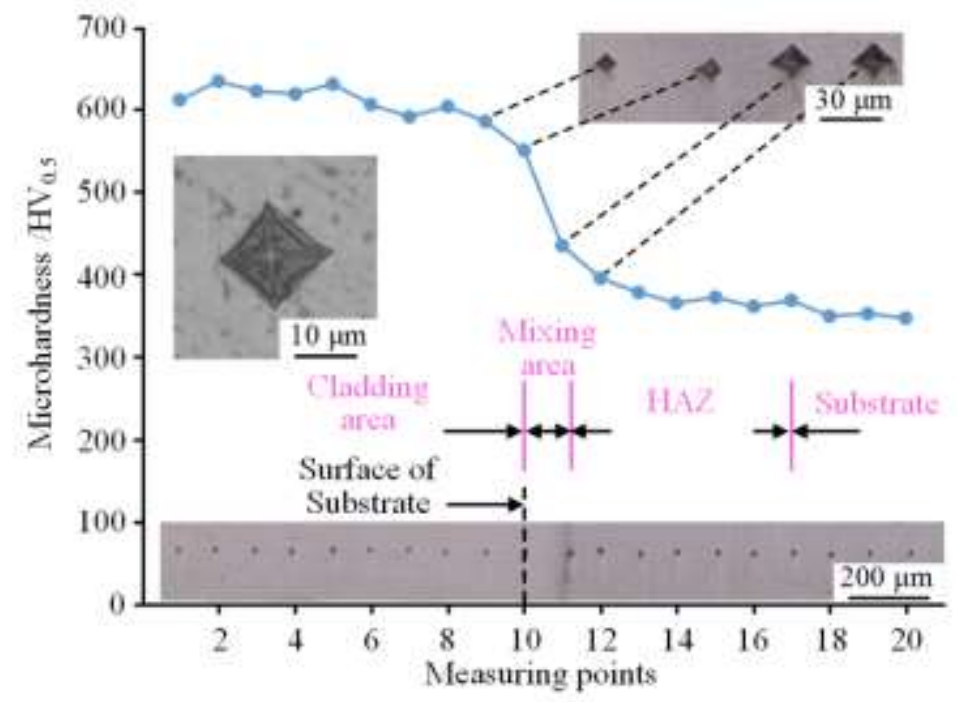

Figure 8 Microhardness change curve of sprocket cladding area

\section{Conclusions}

(1) The main process parameters affecting the cladding high and the cladding zone area are the scanning speed and the powder feeding rate. Scanning speed $V$ is the main influencing factor of the fusion zone area. The change of dilution ratio is mainly affected by the powder feeding rate. The influence of laser power on the geometric characteristics of cladding is weak.

(2) The predictive relationship model between cladding geometry parameters and laser processing parameters can be expressed as the following formula of $y=k\left(P^{\alpha} V^{\beta} F^{\lambda}\right)+b$. The prediction model of cladding high (Hc), cladding zone area $\left(A_{C}\right)$, fusion zone area $\left(A_{m i x}\right)$ and dilution ratio $(D)$ is established respectively with a correlation coefficient $R^{2}$ from 0.8663 to 0.9365 . All the predicted models show strong correlation and small residual value.

(3) A laser remanufacturing multi-objective optimization problem was constructed with maximizing cladding high $\left(H_{C}\right)$, maximizing cladding zone area $\left(A_{C}\right)$, minimizing fusion zone area $\left(A_{m i x}\right)$ and minimizing dilution ratio $(D)$. The optimization model of multi-objective process parameters for laser remanufacturing of sprocket tooth is solved by 
MOPSO algorithm. The optimal process parameters of sprocket remanufacturing are laser power $P=1150 \mathrm{~W}$, scanning speed $V=950 \mathrm{~mm} / \mathrm{min}$ and powder feeding rate $F=3.8 \mathrm{rad} / \mathrm{min}$.

(4) After repairing, the sprocket tooth cladding area is well metallurgically bonded with the substrate, and there are no microcracks or porosity defects generated. The microhardness decreases gradually from the cladding area to the heataffected region and the substrate. The microhardness of the cladding area can reach $550 \mathrm{HV} \sim 650 \mathrm{HV}$, which is particularly superior to the substrate $(350 \mathrm{HV})$.

\section{Ethical Approval}

Not applicable.

\section{Consent to Participate}

Not applicable.

\section{Consent to Publish}

Not applicable.

\section{Authors Contributions}

Chenguang Guo: Investigation, Resources, Writing - Original Draft. Ning Lv: Formal analysis, Software, Investigation, Writing - Original Draft. Haitao Yue: Conceptualization, Methodology, Supervision, Writing - Review \& Editing. Qiang Li: Supervision, Data Curation. Jianzhuo Zhang: Validation, Resources.

\section{Funding}

This research is supported by the National Natural Science Foundation of China (Grant No. 51674134), the Natural Science Foundation of Liaoning Province (Grant No. 20180550167), the Key Projects of Liaoning Province (Grant Nos. LJ2017ZL001 and LJ2019ZL005).

\section{Competing Interests}

The authors declared that they have no conflicts of interest to this work. We declare that we do not have any commercial or associative interest that represents a conflict of interest in connection with the work submitted.

\section{Availability of data and materials}

We certify that we have participated sufficiently in the work to take public responsibility for the appropriateness of the experimental design and the collection, analysis, and interpretation of the data.

\section{References}

[1] Z.M. Zhong, S.J. Clouser. (2014) Nickel-tungsten alloy brush plating for engineering applications. Surface \& Coatings Technology, 240:380-386.

[2] A.H. Liu, X.H. Tang, F.G. Lu. (2013) Study on welding process and prosperities of AA5754 Al-alloy welded by double pulsed gas metal arc welding. Materials and Design, 50:149-155.

[3] R. Juraj, A. Panda. (2017) Thermal Spraying: Plasma and Thermal Spraying. Berlin: Springer International Publishing.

[4] J. Jozwik, K. Dziedzic, I. Usydus, D. Ostrowski, G.M. Krolczyk. (2018) Assessment of internal defects of hardfacing coatings in regeneration of machine parts. J. Cent. South Univ, 25:1144-1153.

[5] B.T. Richards, H.N.G. Wadley. (2014) Plasma spray deposition of tri-layer environmental barrier coatings. Journal of the European Ceramic Society, 34 (12):3069-3083. 
[6] M. Nabhani, R.S. Razavi, M. Barekat. (2018) An empirical-statistical model for laser cladding of Ti-6Al-4V powder on Ti-6Al-4V substrate. Optics and Laser Technology, 100:265-271.

[7] H.M. Liu, X.P. Qin, S. Huang, Z. Hu, M. Ni. (2018) Geometry modeling of single track cladding deposited by high power diode laser with rectangular beam spot. Optics and Lasers in Engineering, 100:38-46.

[8] X.H. Zhan, Y. Meng, J.J. Zhou, C. Qi, C. Zhang, D. Gu. (2018) Quantitative research on microstructure and thermal physical mechanism in laser melting deposition for Invar alloy. Journal of Manufacturing Processes, 31:221-231.

[9] B. Rottwinkel, C. NÖlke, S. Kaierle, V. Wesling. (2014) Crack repair of single crystal turbine blades using laser cladding technology. ${ }^{\text {rd }}$ International Conference on Through-life Engineering Services, 22:263-267.

[10] A. Ray, K.S. Arora, S. Lester, M. Shome. (2014) Laser cladding of continuous caster lateral rolls: Microstructure, wear and corrosion characterisation and on-field performance evaluation. Journal of Materials Processing Technology, 214:1566- 1575.

[11] J. Tuominen, J. Näkki, H. Pajukoski, J. Miettinen, T. Peltola, P. Vuoristo. (2015) Wear and corrosion resistant laser coatings for hydraulic piston rods. Journal of Laser Applications, 27:022009.

[12] F.C. Robles Hernández, A.O. Okonkwo, V. Kadekar, T. Metz, N. Badi. (2016) Laser cladding: The alternative for field thermite welds life extension. Materials \& Design, 111:165-173.

[13] J.L. Song, Q.L. Deng, C.Y. Chen, D.J. Hu, Y.T. Li. (2006) Rebuilding of metal components with laser cladding forming. Applied Surface Science, 252:7934-7940.

[14] H. Qi, M. Azer, P. Singh. (2010) Adaptive toolpath deposition method for laser net shape manufacturing and repair of turbine compressor airfoils. Int J Adv Manuf Technol, 48:121-131.

[15] L. Xu, H.J. Cao, H.L. Liu, Y.B. Zhang. (2016) Study on laser cladding remanufacturing process with $\mathrm{FeCrNiCu}$ alloy powder for thin-wall impeller blade. Int J Adv Manuf Technol, 90:1383-1392.

[16] X. Penaranda, S. Moralejo, A. Lamikiz, J. Figueras. (2017) An adaptive laser cladding methodology for blade tip repair. Int J Adv Manuf Technol, 92:4337-4343.

[17] S. Kaierle, L. Overmeyer, I. Alfred, B. Rottwinkel, J. Hermsdorf, V. Wesling, N. Weidlich. (2017) Single-crystal turbine blade tip repair by laser cladding and remelting. CIRP Journal of Manufacturing Science and Technology, 19:196-199.

[18] H.M. Liu, Z.Q. Hu, X.P. Qin, Y.L. Wang, J. Zhang, S. Huang. (2017) Parameter optimization and experimental study of the sprocket repairing using laser cladding. Int J Adv Manuf Technol, 91:3967-3975.

[19] W. Ya, B. Pathiraj, S. Liu. (2016) 2D modelling of clad geometry and resulting thermal cycles during laser cladding. J Mater Process Technol, 230:217-232.

[20] Y. Huang. (2011) Characterization of dilution action in laser-induction hybrid cladding. Optics \& Laser Technology, 43:965-973.

[21] J. Marzban, P. Ghaseminejad, M.H. Ahmadzadeh, R. Teimouri. (2015) Experimental investigation and statistical optimization of laser surface cladding parameters. Int J Adv Manuf Technol, 76:1163-1172.

[22] J.J. Shi, P. Zhu, G.Y. Fu, S.H. Shi. (2018) Geometry characteristics modeling and process optimization in coaxial laser inside wire cladding. Optics and Laser Technology, 101:341-348.

[23] M. Ansari, R.S. Razavi, M. Barekat. (2016) An empirical-statistical model for coaxial laser cladding of NiCrAlY powder on Inconel 738 superalloy. Optics \& Laser Technology, 86:136-144. 
[24] T.B. Yu, Y. Zhao, J.Y. Sun, Y. Chen, W.R. Qu. (2018) Process Parameters optimization and mechanical properties of forming parts by direct laser fabrication of YCF101 alloy. Journal of Materials Processing Tech, 262:75-84.

[25] H.E. Cheikh, B. Courant, S. Branchu, J.Y. Hascoët, R. Guillén. (2012) Analysis and prediction of single laser tracks geometrical characteristics in coaxial laser cladding process. Optics and Lasers in Engineering, 50(3):41322.

[26] M. Barekat, R.S. Razavi, A. Ghasemi. (2016) Nd:YAG laser cladding of Co-Cr-Mo alloy on Y-TiAl substrate. Optics \& Laser Technology, 80:145-152.

[27] W. Xi, B. Song, Y. Zhao, T.B. Yu, J. Wang. (2019) Geometry and dilution rate analysis and prediction of laser cladding. Int J Adv Manuf Technol, 103:4695-4702.

[28] T. Thepsonthi, T. Özel. (2012) Multi-objective process optimization for micro-end milling of Ti-6Al-4V titanium alloy. Int J Adv Manuf Technol, 63:903-914.

[29] H. Liu, J.B. Hao, Z.T. Han, G. Yu, X.L. He, H.F. Yang. (2016) Microstructural evolution and bonding characteristic in multi-layer laser cladding of NiCoCr alloy on compacted graphite cast iron. Journal of Materials Processing Technology, 232:153-164. 


\section{Figures}

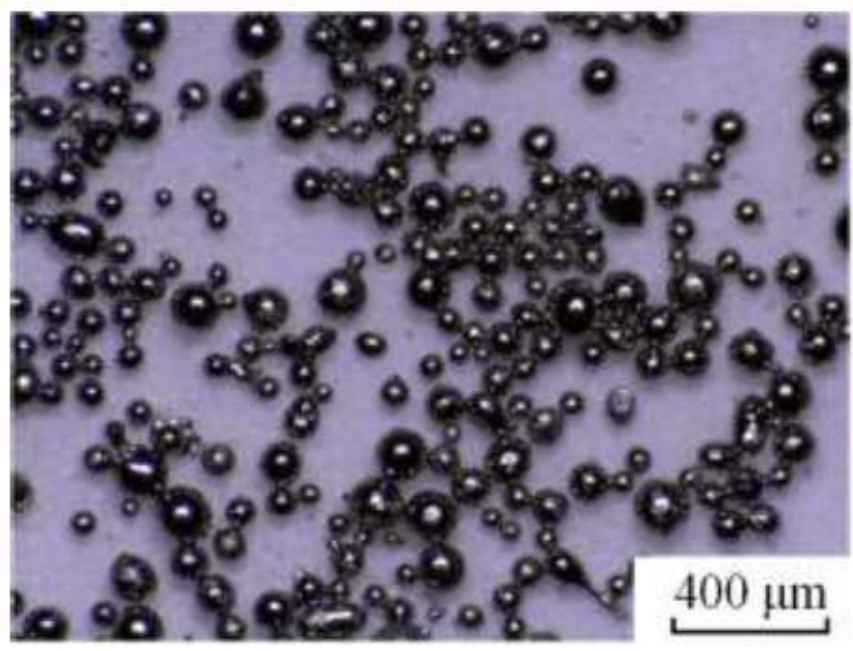

(a) Morphology of powder

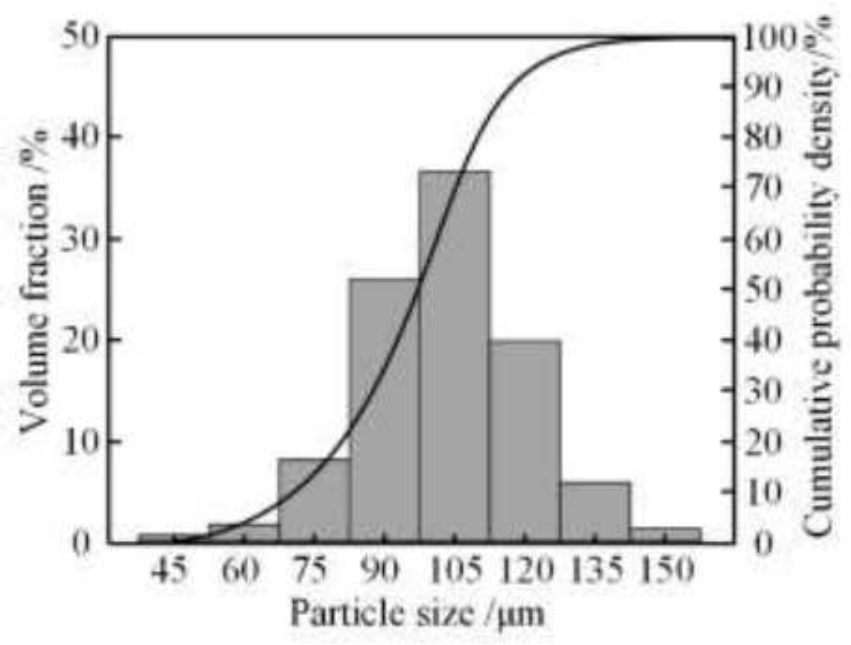

(b) Particle size

\section{Figure 1}

The morphology and particle size of cladding powder material

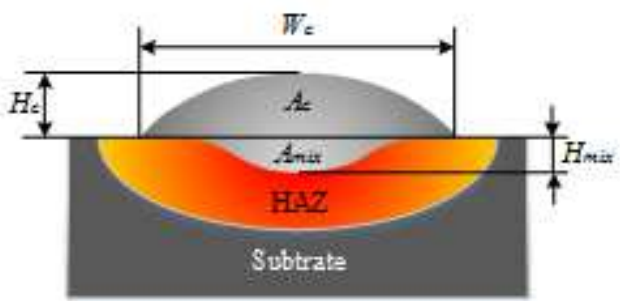

Figure 2

Schematic of single cladding track cross-section 


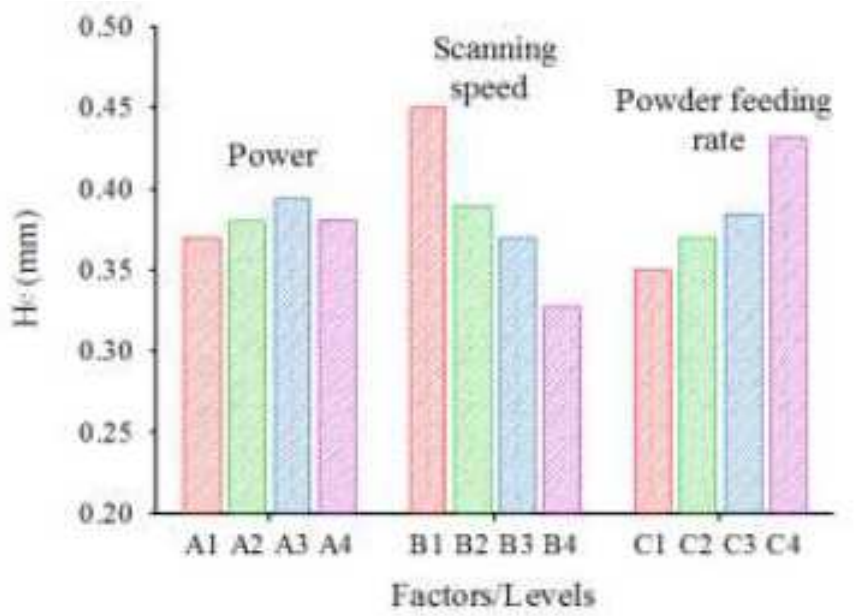

(a)

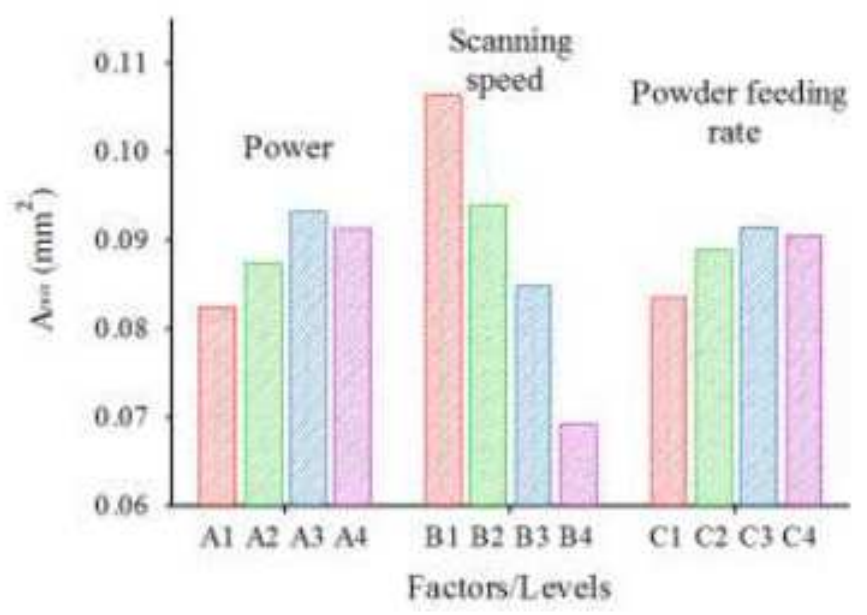

(c)

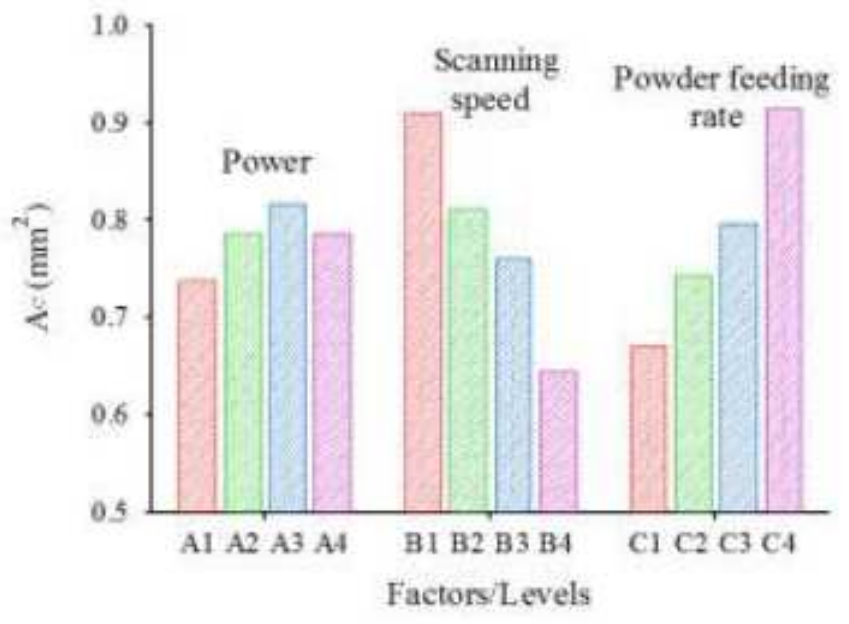

(b)

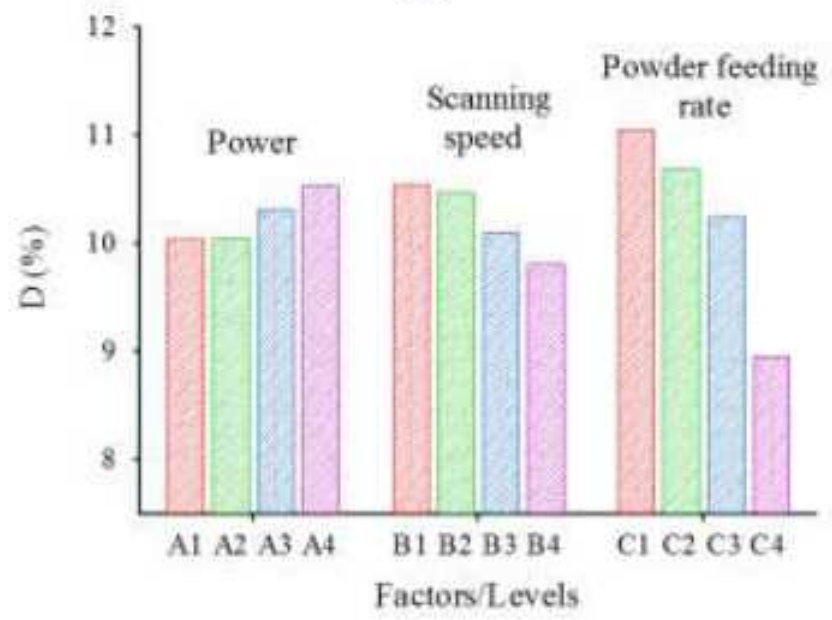

(d)

Figure 3

The trend chart of geometric characteristics and dilution rate 


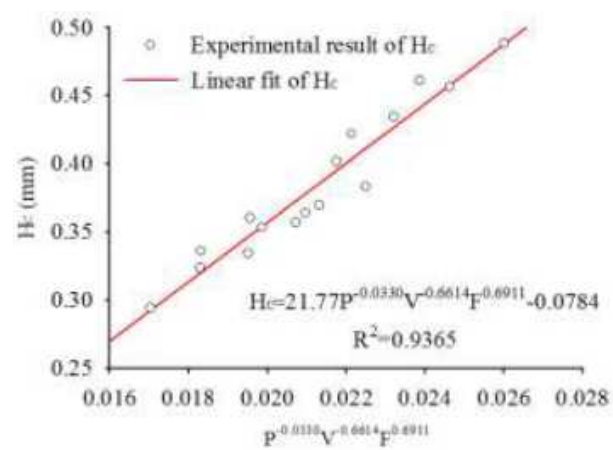

(a)

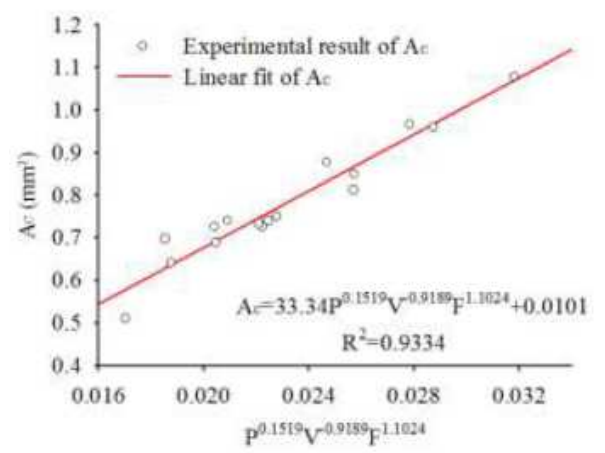

(c)

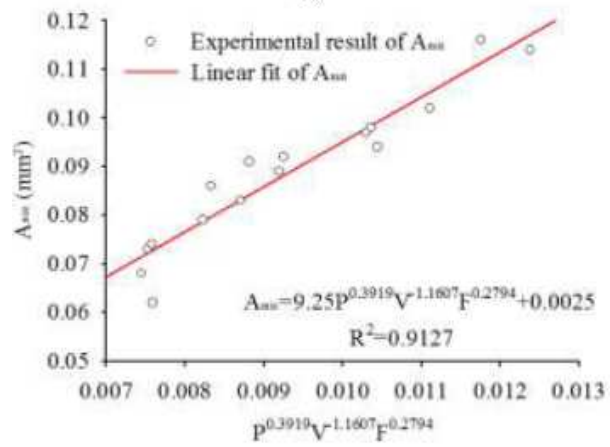

(e)

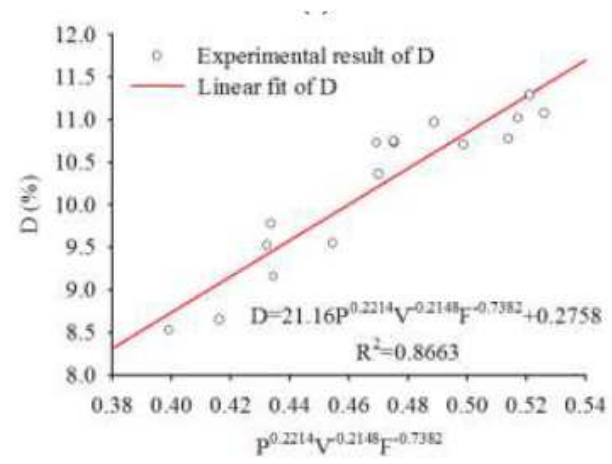

(g)

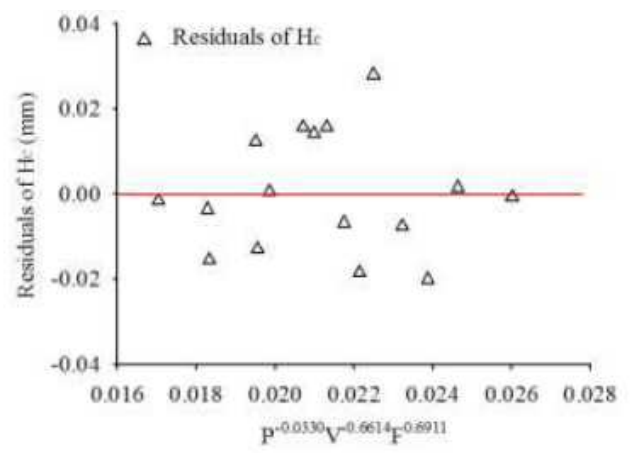

(b)

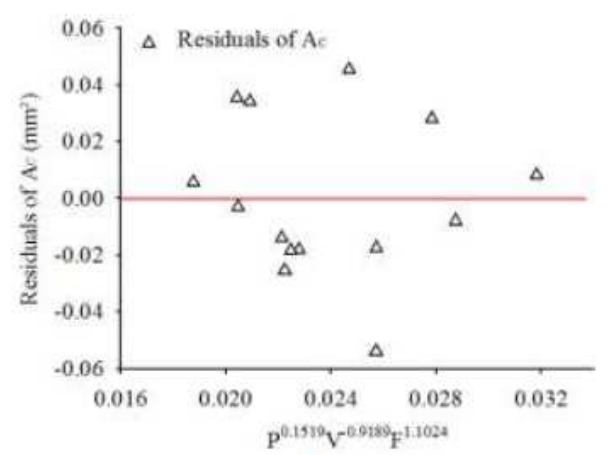

(d)

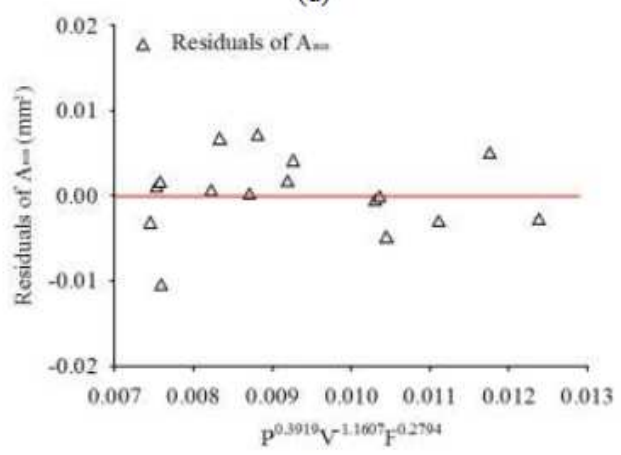

(f)

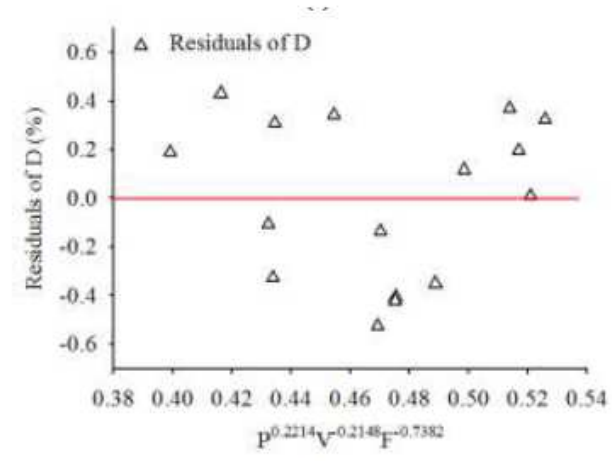

(h)

\section{Figure 4}

Prediction model between $\mathrm{HC}, \mathrm{AC}, \mathrm{Amix}, \mathrm{D}$ with process parameters and residuals 


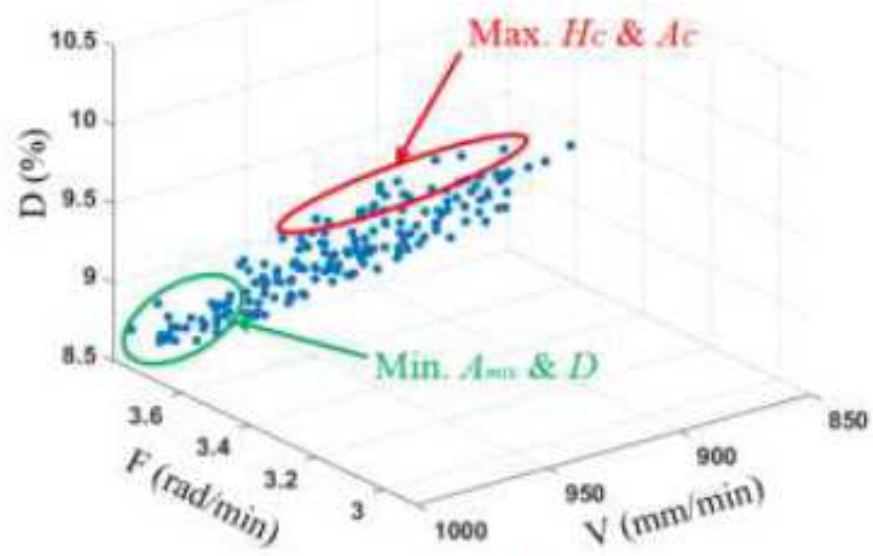

(a) Dilution ratio

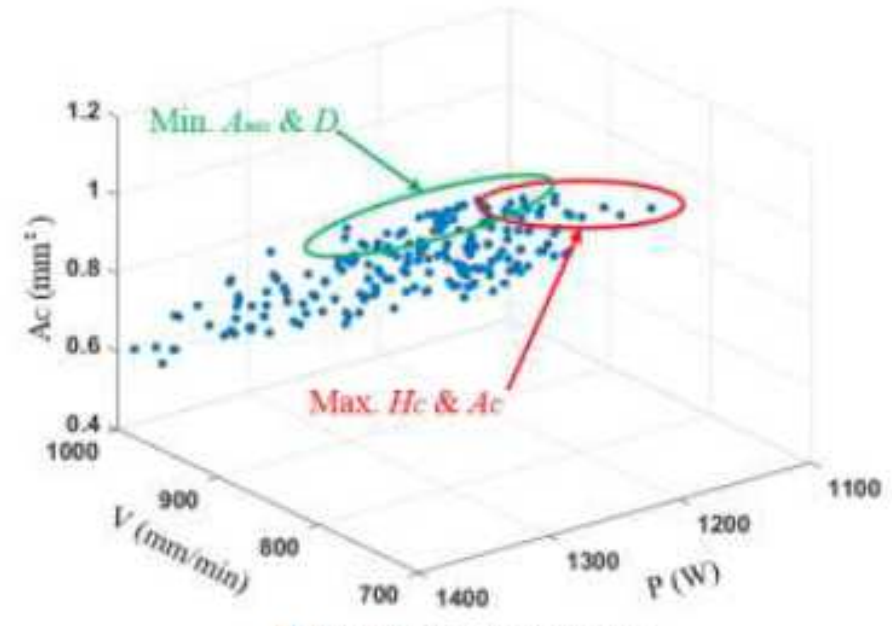

(b) Cladding zone area

\section{Figure 5}

Multi-objective model optimization results
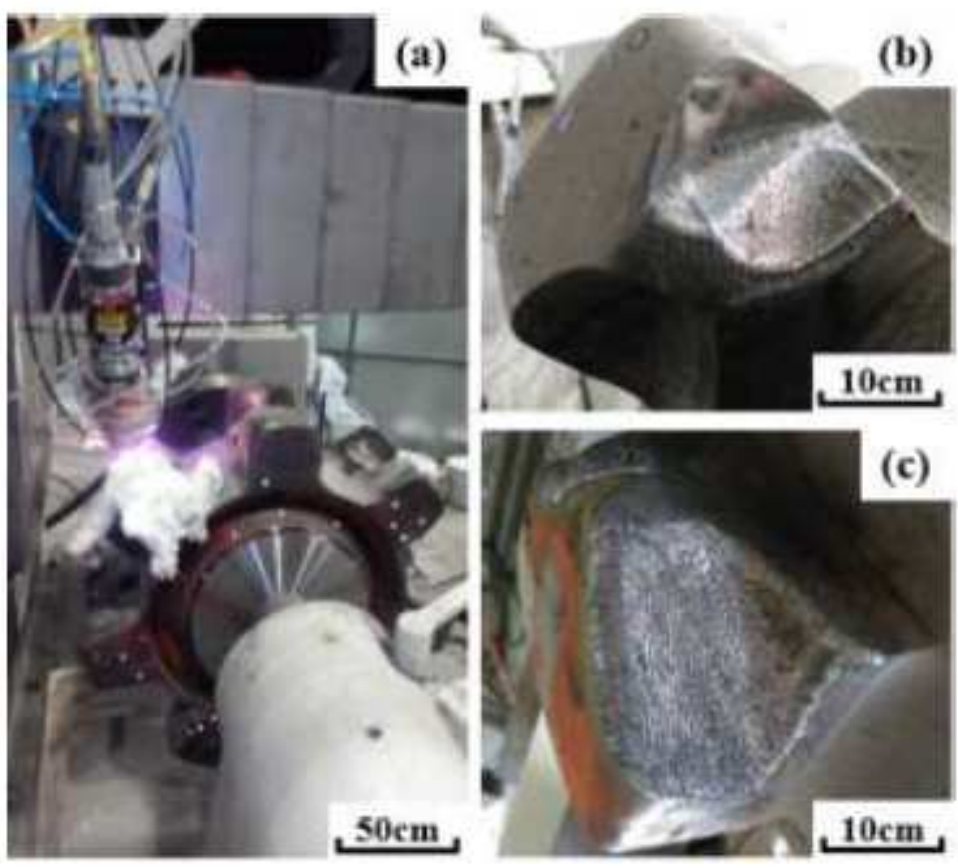

\section{(c)}

Figure 6

Sprocket remanufacturing process and its repair state 


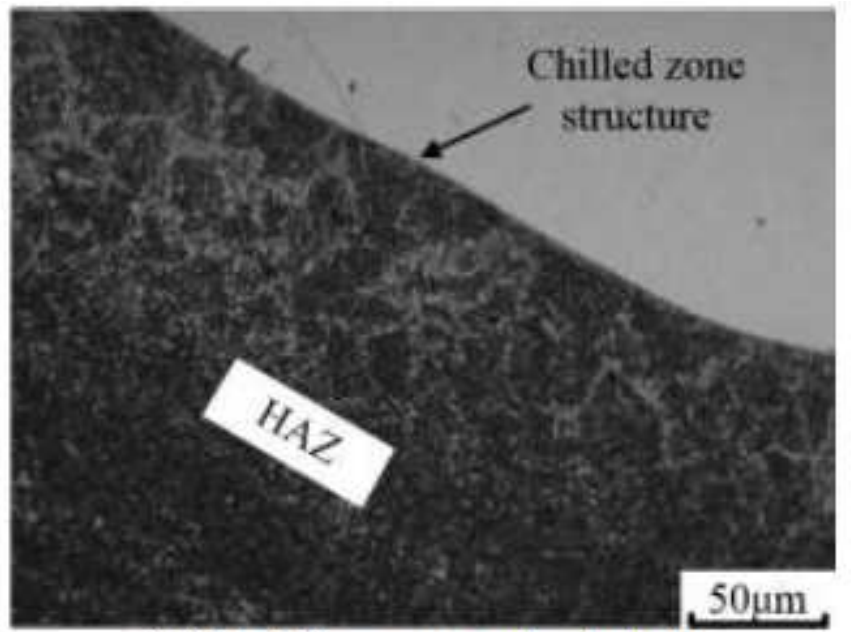

(a) Cladding zone and substrate

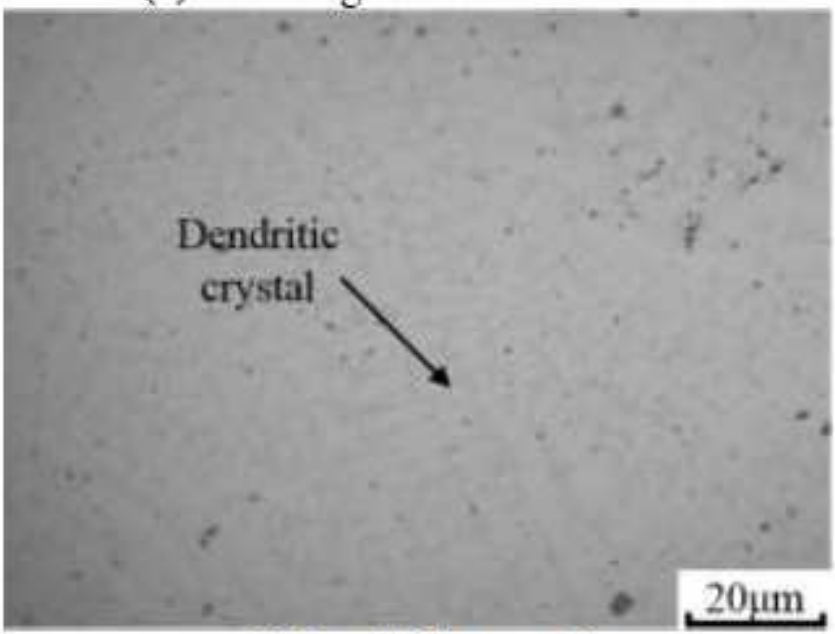

(c) Dendritic crystal

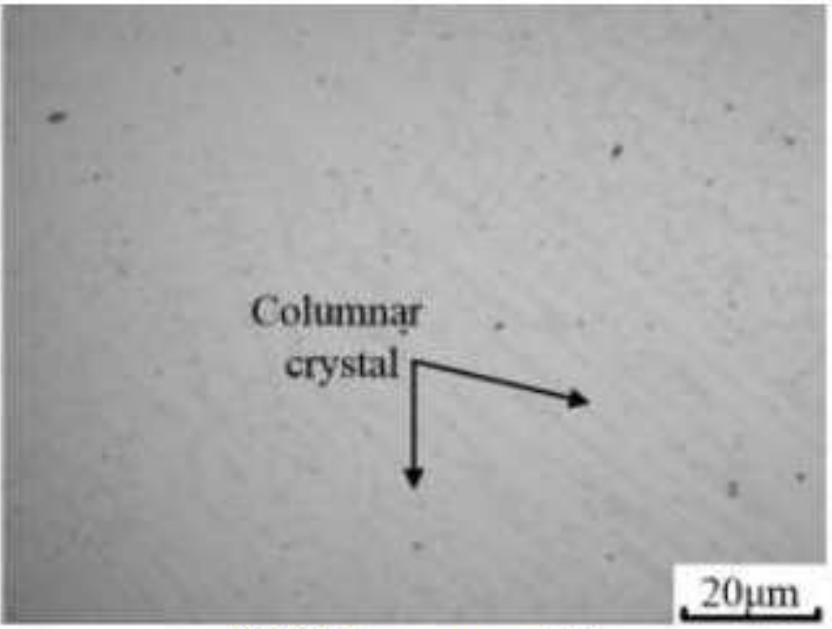

(b) Columnar crystal

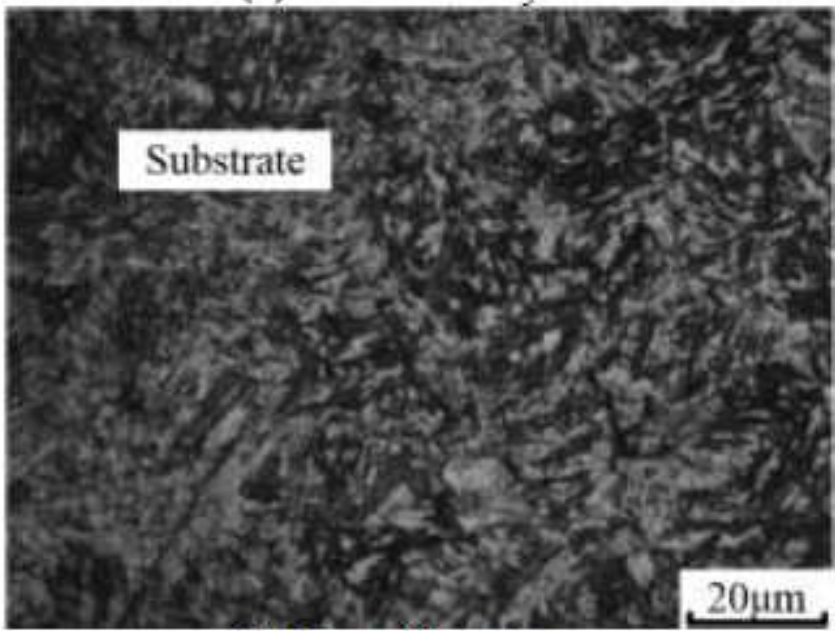

(d) Heat-affected zone

\section{Figure 7}

Metallographic morphology of the cladding area

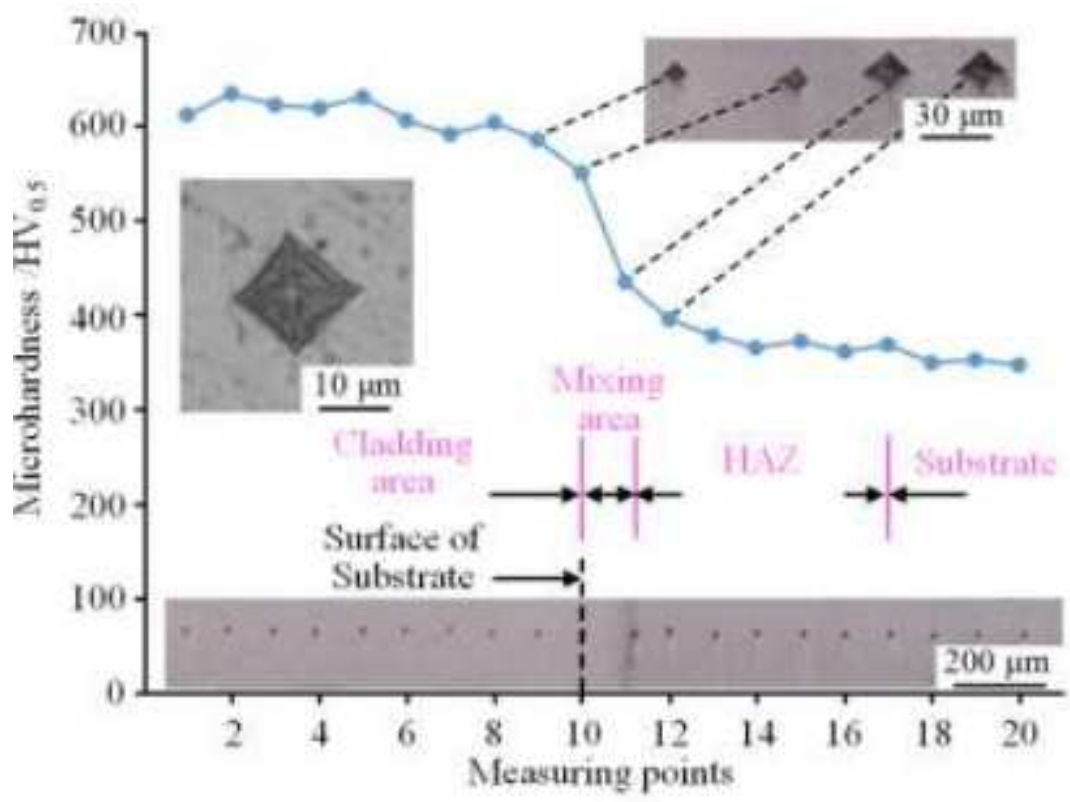

Figure 8 
Microhardness change curve of sprocket cladding area

\section{Supplementary Files}

This is a list of supplementary files associated with this preprint. Click to download.

- Graphicalabstract.tif 